\title{
Processo de Desenvolvimento de Software Educacional: proposta e experimentação
}

Fabiane Barreto Vavassori Benitti* Everton Flávio Rufino Seara ${ }^{* *}$ Luciane Maria Schlindwein ${ }^{* * *}$

Resumo. Pode-se dizer que praticamente todas as partes da sociedade têm sido atingidas pelos avanços tecnológicos. Estudos em informática na educação demonstram que o computador pode potencializar o aprendizado em vários aspectos. Entretanto, desenvolver um software educacional (SE) que supra todas as necessidades de uma perspectiva pedagógica, é uma tarefa árdua, tendo em vista que para isto é necessário seguir uma série de etapas para que o mesmo atinja inteiramente seu objetivo. Este artigo apresenta uma metodologia de desenvolvimento de software educacional, uma vez que a construção de um SE aborda questões específicas que diferem dos sistemas tradicionais e, portanto, devem ser consideradas em sua concepção.

Palavras Chave. informática na educação, software educacional, engenharia de software, processo de desenvolvimento.

\section{Educational Software Development Process: proposal and experimentation}

\begin{abstract}
It is possible to say that all the parts of the society has practically been reached by the technological advances. Studies, in Computer Science in Education, demonstrate that the computer can improve the learning in several aspects. However, to develop educational software that supply all the necessities of a pedagogical perspective, it is a hard task, considering that for this a set of stages are necessary in order to reach its objective completely. This article presents a methodology of educational software development, once that its development appoaches specific questions that differ from traditional systems, and, thus, they should be considered in its conception..
\end{abstract}

Keywords. computing education, educational software, software engineering, development process.

\section{Introdução}

Este artigo apresenta uma proposta metodológica para o processo de desenvolvimento de software educacional que compreende tanto aspectos técnicos quanto pedagógicos. Tendo em vista que diversos estudos, Ramos (2003), têm demonstrado que a utilização da Informática na Educação pode potencializar e auxiliar o processo de ensino-aprendizagem nas escolas e que a informática vem impregnandose cada vez mais nos ambientes escolares, se faz necessário a concepção de um padrão de desenvolvimento de software educacional, para que os mesmos possam contemplar as reais necessidades dos docentes em uma determinada perspectiva pedagógica.

Giraffa e Viccari (1998) citadas por Bertoletti et al (2001) afirmam que, software educacional é um programa que visa atender necessidades, possui fins pedagógicos definidos e está inserido em um contexto de ensino-aprendizagem.

\footnotetext{
* Doutora. Professora na área de Engenharia de Software. Universidade do Vale do Itajaí (UNIVALI) Rua Uruguai, 458 - Bairro Centro - Itajaí - SC - Brasil - Cep: 88.302-202 e Universidade Regional de Blumenau (FURB) - Rua: Braz Wanka, 238 - Bairro Vila Nova - Blumenau - SC - Brasil - Cep: 89035160. fabiane.benitti@univali.br

*** Bolsista CNPq. Universidade do Vale do Itajaí (UNIVALI) - Rua Uruguai, 458 - Bairro Centro - Itajaí SC - Brasil - Cep: 88.302-202. everton.Flavio@univali.br

"* Doutora. Coordenadora e Professora de Mestrado em Educação. Universidade do Vale do Itajaí (UNIVALI) - Rua Uruguai, 458 - Bairro Centro - Itajaí - SC - Brasil - Cep: 88.302-202. lucmas@univali.br. V. $3 \mathrm{~N}^{\circ} 1$, Maio, 2005
} 
Todavia, os softwares educacionais existentes - em sua grande maioria - possuem problemas que dificultam a sua utilização, dentre eles a falta de uma base pedagógica que fundamente sua construção. Sendo assim, o processo proposto compreende além de questões pertinentes processos de software, que segundo Martin (1991) citado por Trebien (2003) é a fase relativa à forma pela qual os processos selecionados são implementados em procedimentos e como esses funcionam, aspectos relativos a concepção de software educacional coerente com uma perspectiva pedagógica, formação de uma equipe multidisciplinar de desenvolvimento, o processo de validação, bem como a formação docente.

No contexto atual, a seção 2 deste artigo define o processo de desenvolvimento de software educacional. A seção 3 apresenta as considerações gerais sobre a concepção do processo e expõe exemplos de aplicações desenvolvidas baseando-se no mesmo. As conclusões são apresentadas na seção 4.

\section{Processo de desenvolvimento}

A proposta apresentada nesta seção expõe um processo para desenvolvimento de software educacional e, portanto, fundamenta-se tanto em conceitos computacionais quanto educacionais, promovendo a integração entre ambas as áreas visando um produto de qualidade, referenciado em uma proposta pedagógica definida.

O processo de desenvolvimento é basicamente constituído de 4 (quatro) etapas principais: (i) concepção, (ii) elaboração, (iii) finalização e (iv) viabilização. Cada etapa possui um foco bem definido, conforme apresentado na figura 1.

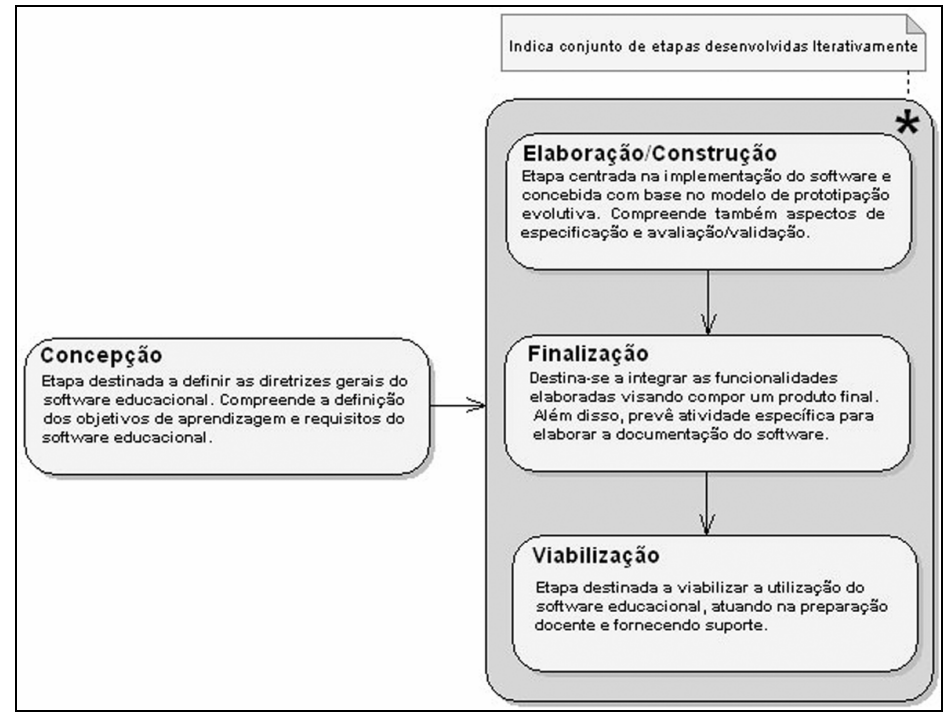

Figura 1 - Visão geral da metodologia

Em termos computacionais, considera-se adequado o desenvolvimento de software educacional de forma iterativa e incremental, quando são observados os seguintes aspectos:

$\checkmark$ Incremental, levando-se em consideração a visão de Sommerville (2003), o qual define que o software terá o seu escopo definido na primeira etapa, no caso conjuntamente entre educadores e desenvolvedores, sendo posteriormente dividido em estágios para entrega. Viabilizando, desta forma, a validação dos objetivos de aprendizagem para cada estágio do software, conforme é detalhado em seções posteriores.

$\checkmark$ Iterativo, baseado na definição de Sommerville (2003, p. 43) "em que partes do processo são repetidas", sendo aplicado às 3 últimas etapas do processo proposto. Sendo 
assim, também é considerado que "não há uma especificação completa do sistema até que o estágio final seja especificado" (SOMMERVILLE, 2003, p.43).

A nomenclatura das etapas e a definição do processo apresentam semelhanças com o Unified Process (IBM SOFTWARE, 2004), existindo inclusive atividades equivalentes. No entanto, o processo proposto comporta especificidades vinculadas principalmente ao contexto educacional, que podem ser claramente identificadas nas seções que detalham as etapas.

As seções seguintes especificam as atividades e atores envolvidos em cada etapa proposta no processo. No entanto, é conveniente definir inicialmente os atores que caracterizam um grupo multidisciplinar voltado ao desenvolvimento de software educacional:

$\checkmark$ Profissionais da Educação: representação abstrata de dois atores específicos que devem estar envolvidos no desenvolvimento de software educacional. Refere-se especificamente a:

\$ Profissionais (pesquisadores) das áreas de psicologia e pedagogia: constitui em especialistas em Educação, especialmente na área do currículo e da aprendizagem.

\$ Professores: todo o software educacional está vinculado a uma realidade de ensino, o qual é diariamente trabalhado por professores. Tal participação legitima o conteúdo do software, uma vez que os professores se constituem em usuários em potencial. De acordo com Wishart \& Blease (1999) citado por Hinostroza \& Mellar (2001), tradicionalmente o desenvolvimento de softwares educacionais, quando conta com a participação de professores, sua contribuição volta-se a aspectos referentes a aprendizagem ou a propostas curriculares, negligenciando a prática de sala de aula. Sendo assim, participação de professores neste processo de desenvolvimento há que considerar também este aspecto.

$\checkmark$ Profissionais da área computacional: profissionais da área de Engenharia de Software e Programação, com conhecimento de técnicas aplicadas ao processo de desenvolvimento (tais como: métodos de especificação de requisitos, análise e projeto orientado a objeto, técnicas de testes de software), linguagem de programação, e também em tecnologias específicas do domínio da aplicação (como por exemplo, interface em 3D).

$\checkmark$ Designer: voltado à construção da interface do software, devendo possuir conhecimento na área de usabilidade e dominar ferramentas para desenvolvimento gráfico, animações e som.

$\checkmark$ Aluno (usuário): representa uma amostra significativa relativa ao contexto de aplicação do software. Conforme apresentado na seção 2.2, sua atuação no processo está centrada na validação do software educacional.

\subsection{Concepção}

A etapa de concepção define as diretrizes do software educacional partindo do estabelecimento dos objetivos de aprendizagem do software e organizando-os em requisitos computacionais. Para tanto, os profissionais da área computacional e da educação são fundamentais. Cabe aos profissionais da educação conduzir a discussão em torno dos objetivos de aprendizagem que nortearam a concepção do software subsidiando a definição dos requisitos computacionais, descritos pelos profissionais da área de computação.

A primeira atividade da etapa de concepção concentra-se em definir os objetivos de aprendizagem e requisitos do software, além de definir o escopo, o público alvo e identificar a infra-estrutura disponível na escola. Após a definição desta atividade, particiona-se, quando viável, os requisitos identificados em estágios. Cada estágio deve constituir um incremento do processo e ser operacional, ou seja, possuir uma gama de 
funcionalidades que possam ser utilizadas de forma independente. Como resultados da execução completa desta etapa são gerados dois documentos:

$\phi$ Visão Geral;

Planejamento geral do software educacional:

\& Infra-estrutura disponível;

\$ Características do público alvo;

\& Objetivos de aprendizado;

$\phi$ Requisitos do Software.

$\checkmark$ Planejamento do Processo:

$\phi$ Identificação dos estágios e divisão dos requisitos do software;

$\phi$ Cronograma geral.

A partir de então é possível iniciar a etapa de elaboração para cada incremento. A figura 2 apresenta de forma resumida a etapa de concepção, suas atividades e os atores responsáveis por sua execução, bem como o nível de interação dos mesmos.

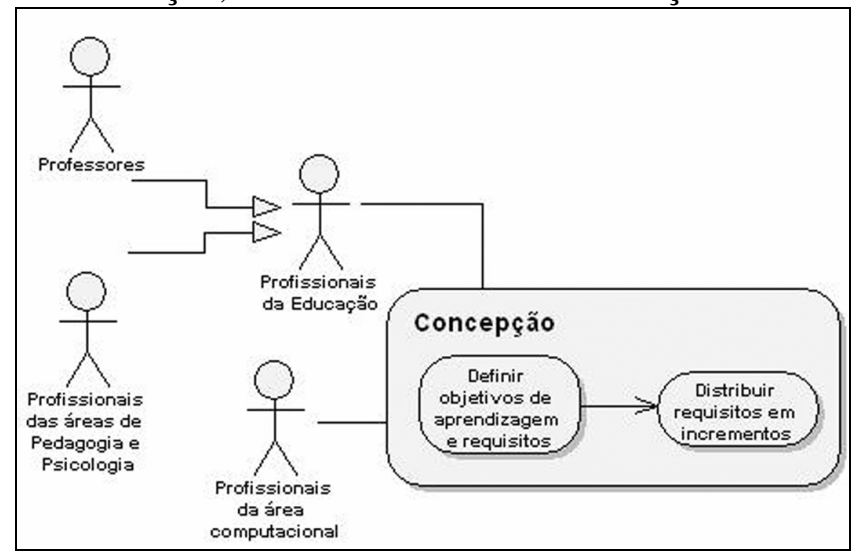

Figura 2 - Detalhamento da etapa de concepção

Analisando as particularidades existentes em cada área de conhecimento presente no processo de desenvolvimento de software educacional, observa-se que os atores possuem, na maioria dos casos, linguagens próprias e distintas.

Para o desenvolvimento de um software educacional várias adequações são essenciais, iniciando pela linguagem, já que cada área possui um "repertório lingüístico" próprio e o processo de desenvolvimento envolve um espaço colaborativo. Deste modo, quando não há sedimentada uma base comum de comunicação, recomenda-se o estabelecimento de diálogos entre os conhecimentos de informática e fundamentos pedagógicos, assim pode-se nivelar a linguagem dos envolvidos, entrecruzar conhecimentos e moldar um processo formativo único.

\subsection{Elaboração}

Constitui-se na etapa mais longa do processo de desenvolvimento, tendo em vista que abrange atividades de implementação, avaliação e validação do software. Tem como objetivo específico a criação de um protótipo funcional do software educacional norteado pelos requisitos identificados na etapa de concepção. Esta etapa, como apresenta a figura 3, subdivide-se basicamente em quatro atividades: 


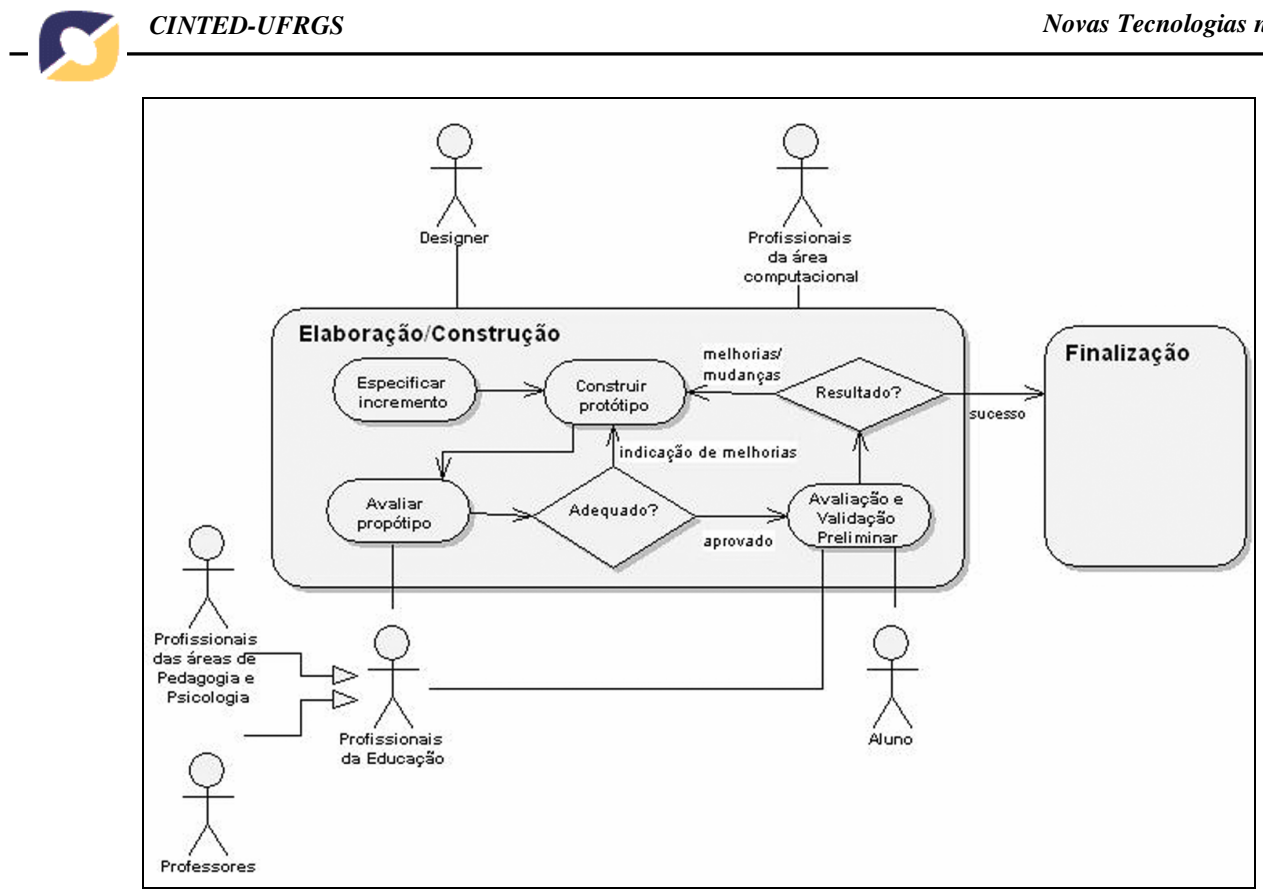

Figura 3 - Detalhamento da etapa de elaboração/construção

Especificar incremento: Nesta atividade estão envolvidos profissionais da área computacional e de design, já que, segundo Simões (2003), aspectos de interface devem ser amplamente considerados quando se trata de desenvolvimento de software educacional. Esta atividade tem como objetivo principal detalhar os requisitos do software levantados na etapa de concepção, e criar uma especificação inicial do software. Além disso, é pertinente a esta atividade uma pesquisa tecnológica, com o intuito de definir a tecnologia mais indicada para implementação do sistema.

$\checkmark$ Construir protótipo: Realizada integralmente por profissionais da área computacional e de design. Consiste no estágio de desenvolvimento do protótipo do software, utilizando para isto, as tecnologias selecionadas na atividade anterior. Esta atividade também é responsável por elaborar a interface com o usuário, com o intuito de conceber softwares atrativos e observando aspectos de usabilidade. Como resultado desta atividade, tem-se um protótipo do incremento do software, que será posteriormente avaliado.

$\checkmark$ Avaliar protótipo: Após a geração do protótipo na atividade de construção é realizada uma avaliação, onde participam além dos profissionais da área computacional e de design, profissionais de Educação com o intuito de sugerir melhorias avaliando aspectos como: funcionalidade, usabilidade, performance e potencial pedagógico (destacadamente aspectos de ensino e de aprendizagem). Uma vez aprovado o protótipo, inicia-se a execução da próxima atividade (validação preliminar), caso contrário, o fluxo retorna a construção do protótipo.

$\checkmark$ Validação preliminar: A validação preliminar do software, além da participação dos profissionais da computação e educação, envolve também a figura do aluno, que neste caso, é peça fundamental. Esta atividade é realizada nas escolas envolvendo uma amostra que caracterize o público alvo definido na etapa inicial, selecionando-se, preferencialmente, instituições de ensino que incorporem professores participantes da equipe de desenvolvimento do software. O foco desta atividade é voltado ao uso do software educacional pelos alunos, estando centrado em dois focos: (i) validação, no qual são analisados aspectos como funcionalidade, usabilidade, confiabilidade e eficiência do software e (ii) avaliação, voltada aos objetivos de aprendizagem propostos na etapa de concepção. Caso o processo de validação seja positivo ou sejam sugeridas 
pequenas mudanças, a etapa seguinte (finalização) pode ser executada para o incremento recém validado, caso contrário deve-se retornar a atividade de construção.

Observa-se claramente na figura 3 o processo de prototipação evolucionária, que envolve as três primeiras atividades desta etapa, e que segundo Sommerville (2003), é baseada na idéia de desenvolver uma implementação inicial expondo-a aos comentários dos usuários e aperfeiçoando-a ao longo de muitos estágios, até que o sistema adequado tenha sido desenvolvido.

O produto concebido ao término da execução desta etapa é um incremento usual/operacional do software educacional. Recomenda-se também, para uma verificação mais precisa do uso do software, coletar dados estatísticos (número de alunos, professores e escolas, configuração dos equipamentos, etc.) e relatos dos alunos, referentes ao processo de validação do software educacional.

\subsection{Finalização}

Embora esta não seja a última etapa do processo de desenvolvimento, refere-se a parte final de "construção" do software, que somente ocorre após uma análise positiva da avaliação do uso do software educacional pelos alunos. Esta etapa divide-se em duas atividades distintas: (i) integração, realizada pelo profissional da área de computação, que irá verificar se existem pequenos ajustes que tenham sido observados na validação preliminar do software e alterá-los. Também é realizada nesta atividade a integração do incremento ao produto final, caso o mesmo não se refira ao primeiro incremento; (ii) elaborar documentação, é essencial para qualquer software desenvolvido uma documentação detalhada, desde o projeto à implementação. Nesta atividade é gerada uma especificação detalhada do software e é criado um manual do usuário, contendo informações referentes à utilização do software e exemplos de atividades pedagógicas, elaboradas conjuntamente com profissionais da educação, para o uso dos professores. A figura 4 detalha a etapa e a participação de cada ator.

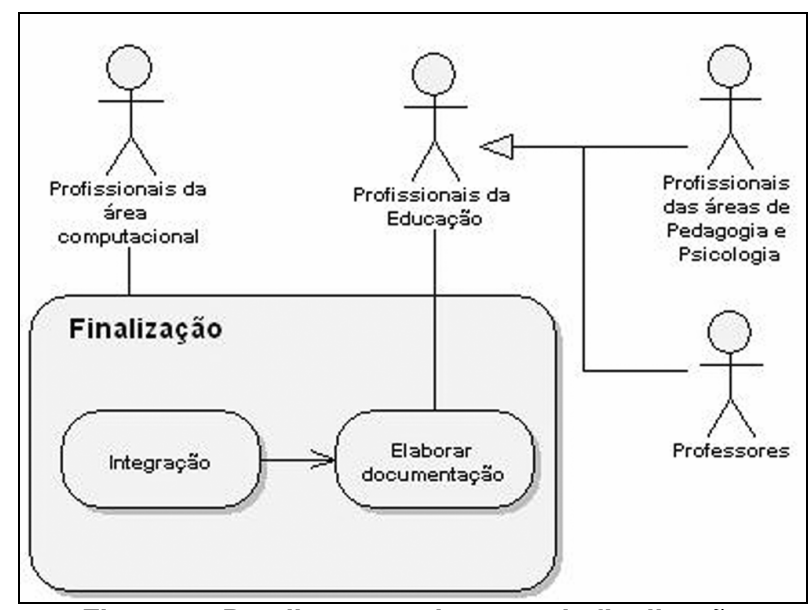

Figura 4 - Detalhamento da etapa de finalização

Ao término desta etapa, o incremento do software estará completo e usual/operacional, podendo ser instalado e utilizado em qualquer ambiente escolar.

\subsection{Viabilização}

Esta é a última etapa do processo de desenvolvimento e é destinada em especial aos usuários do software educacional. Como pode ser visto na figura 5 , os profissionais da área computacional e de educação atuam em conjunto em todas as três atividades da etapa. 


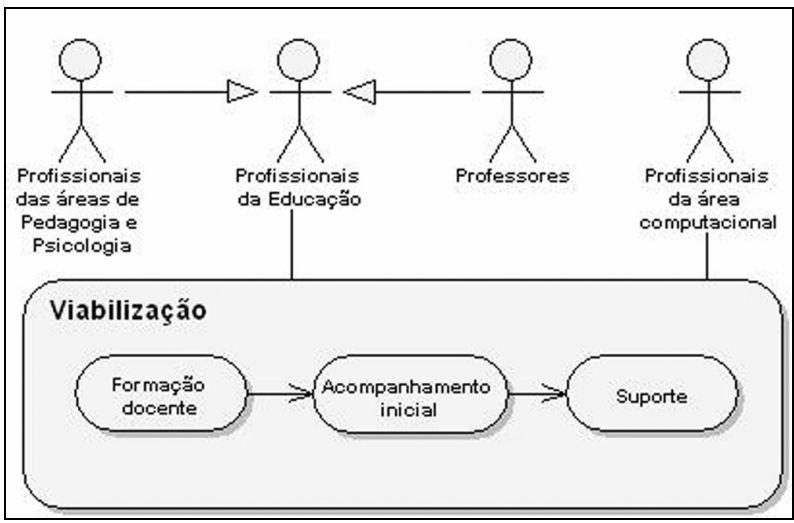

Figura 5 - Detalhamento da etapa de viabilização

A atividade de formação docente objetiva a capacitação dos docentes no que diz respeito ao uso do software educacional, bem como apresenta exemplos de atividades pedagógicas que podem ser integradas em suas aulas, estimulando assim o uso do software. Esta atividade ainda apresenta o software aos docentes como um complemento na aprendizagem do aluno e permite que o professor articule o conteúdo programático previsto em seu plano de ensino com o potencial pedagógico do software.

Durante a formação docente pode ser constatado um redimensionamento dos objetivos de aprendizagem iniciais, ampliando-os, uma vez que, os professores utilizarão o software a partir dos seus referenciais pedagógicos e do contexto educacional em que a escola está inserida. Desta forma, os documentos iniciais podem ser revistos bem como, o manual do usuário pode ser ampliado com novas sugestões de atividades.

Outra atividade de extrema importância nesta etapa é o acompanhamento inicial do uso do software, tendo em vista que existe a possibilidade de que ocorram erros não encontrados nas etapas anteriores. E, no que se refere ao potencial pedagógico do software, a opinião do professor é fundamental, permitindo o dimensionando do uso da ferramenta às suas necessidades (tanto em termos de conteúdos quanto de aplicabilidade) inseridas no cotidiano pedagógico. A atividade final desta etapa e também de todo o processo é o suporte, que é a atividade responsável pela "manutenção" do software, tanto no que diz respeito à tecnologia quanto à pedagogia. Nesta atividade deve-se corrigir os problemas encontrados e fornecer apoio contínuo para o uso do software educacional.

\section{Aplicação do processo de desenvolvimento}

Todas as etapas descritas nas seções anteriores foram desenvolvidas baseando-se no desenvolvimento prático de softwares educacionais, dentre eles um projeto intitulado Softvali, utilizado, neste artigo, para demonstrar a aplicação do processo de desenvolvimento proposto.

O projeto Softvali tem como objetivo principal o desenvolvimento de um software educacional coerente com uma perspectiva pedagógica, tendo sua concepção sido norteada pelas diretrizes pedagógicas da Rede Municipal de Educação de Blumenau/SC. Os atores participantes do processo, referente aos profissionais da educação, são: 1 pesquisadora da área de educação e 6 profissionais da rede pública (contando com professores e técnicos) e 1 bolsista da psicologia (da área escolar). Os atores relativos aos profissionais da computação são: 2 pesquisadores da ciência da computação e 4 bolsistas atuando como programadores. Além destes, consta-se com o ator designer representado por 1 bolsista.

Inicialmente, o grupo traçou como objetivos de aprendizagem estabelecidos para o Softvali o desenvolvimento de habilidades e conhecimentos básicos para as séries 
iniciais do Ensino Fundamental, ou seja, envolvendo conhecimentos de lógica matemática, de linguagem (especialmente em termos de alfabetização) e do contexto social, econômico e estético. Além disso, o software instrumentalizaria o desenvolvimento de habilidades artísticas, seja no âmbito da história da arte, da leitura da obra de arte (e da releitura), seja na própria produção do artefato artístico.

Com base nos objetivos traçados foi definido o contexto do software, o qual baseiase em uma réplica do centro da cidade de Blumenau, prevendo atividades para 25 cenários dispostos na cidade. Até o presente momento, têm-se desenvolvidos três cenários (i) Supermercado, no qual se pode encontrar questões relacionadas à matemática, economia, entre outros conceitos; a Fazenda, onde se encontram perspectivas relacionadas ao meio ambiente e assemelha-se a jogos de RPG (Role Playing Game); Estúdio de Cinema que fornece a possibilidade de construir filmes/histórias e o Museu voltado à construção e visitação de exposições em 3D.

De forma resumida, ao final da primeira etapa havia definido 4 incrementos(estágios) a serem desenvolvidos, cada qual com um objetivo de aprendizagem e requisitos definidos. Os estágios e objetivos são:

$\checkmark$ Supermercado: foco em explorar conhecimentos lógico-matemáticos (especialmente os conceitos de operações básicas e álgebra).

$\checkmark$ Estúdio Cinema: voltado ao desenvolvimento da linguagem, especialmente em termos de alfabetização.

$\checkmark$ Museu: desenvolvimento de habilidades artísticas, explorando o conceito de estética, imaginação e criatividade.

$\checkmark$ Fazenda: voltado ao contexto social e econômico (explorando os conceitos no âmbito da geografia e da história).

Visando ilustrar uma iteração completa do processo de desenvolvimento, este exemplo de aplicação foca o desenvolvimento do cenário Museu. Ao final da primeira etapa, concepção, tinha-se definido o cenário Museu como um ambiente em 3 dimensões e com possibilidade de configuração.

$\mathrm{Na}$ etapa de elaboração, foram estabelecidos os principais requisitos: (i) permitir a visualização de exposições, contendo 8 obras cada, em 3D; (ii) permitir a criação de novas exposições; (iii) viabilizar a alteração e exclusão de exposições e, (iv) dispor as exposições disponíveis sobre a forma de um folder. Quanto aos aspectos tecnológicos, foram analisadas 7 ferramentas/bibliotecas para implementação de ambientes 3D, tendose escolhido a ferramenta Blender (BLENDER 3D, 2004). Além disso, optou-se por utilizar a linguagem $\mathrm{C}++$ e o banco de dados Firebird.

A atividade de construção do protótipo iniciou pelo design em 3D (Figura 6a), tendo sido validado pelo grupo. No entanto, ao testar o protótipo em equipamentos da rede pública, detectou-se problemas de performance. Sendo assim, o protótipo foi remodelado tendo resultado em sua forma final, conforme figura $6 \mathrm{~b}$. Em seguida, em uma nova iteração da atividade de construção, foi desenvolvido o ambiente de configuração, Figura 7a, e o folder de apresentação, $7 \mathrm{~b}$ - ambos aprovados pelo grupo.

Partiu-se, então, para avaliação e validação do incremento (Museu) em 2 (duas) escolas da rede pública de Blumenau. O protótipo final foi utilizado por 66 alunos, na faixa etária de 9 a 12 anos. Com o estágio validado iniciou-se a criação da documentação e manual do usuário (help e caderno de atividades - com sugestões de atividades coerente com a "perspectiva de projetos de trabalho empregada pela rede". Estando o manual concluído foram oferecidos dois cursos de formação aos docentes da rede municipal, tendo participado 15 professores de 10 escolas. Os docentes receberam instruções de uso do software e orientações de aplicações práticas vinculadas ao seu cotidiano. Ao final da formação foram selecionados 2 projetos que foram 
acompanhados pelo grupo, tendo os demais ficado sobre a tutela da secretaria de educação. Atualmente, este cenário (resultado do primeiro incremento do processo de desenvolvimento) está disponível em diversas escolas da rede.

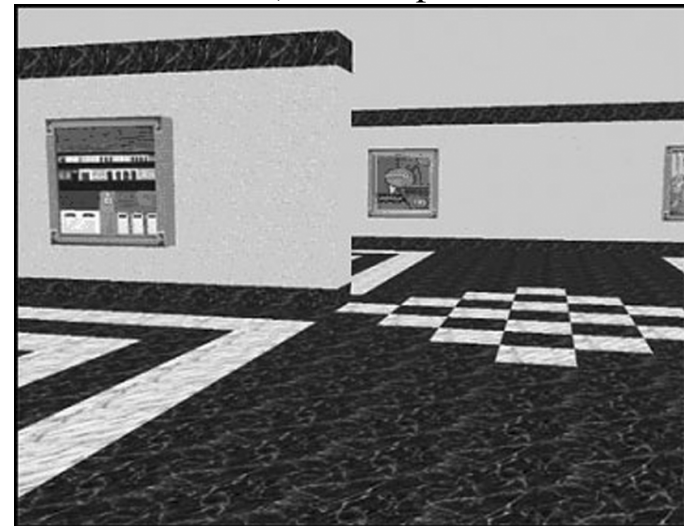

Figura 6(a) - Primeiro protótipo do museu 3D

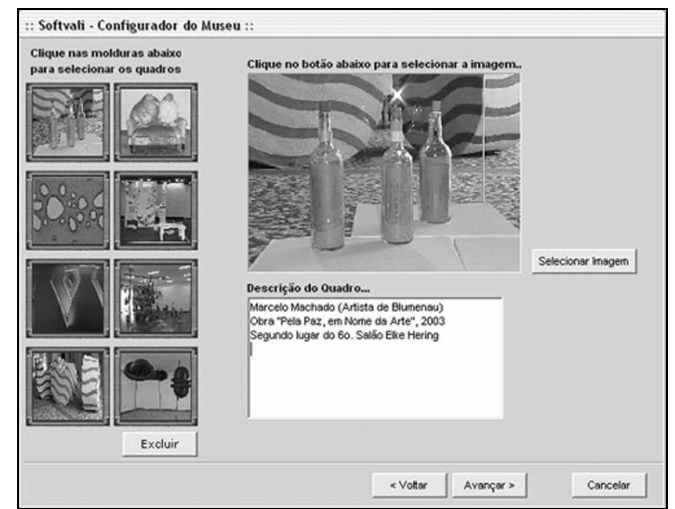

Figura 7(a) - Configurador do museu

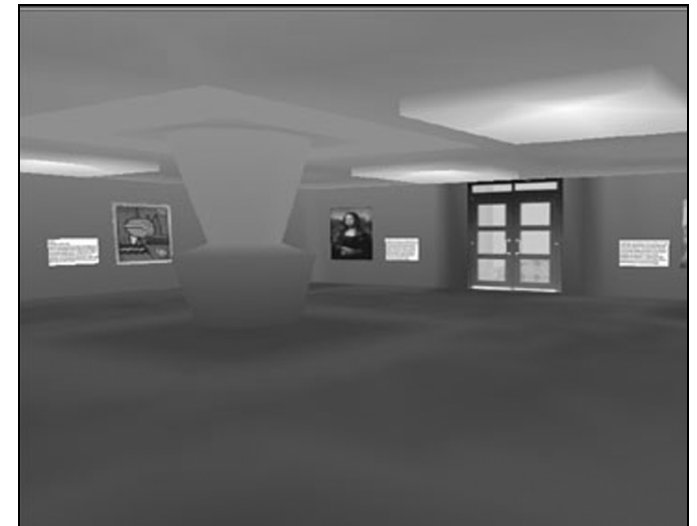

Figura 6(b) - Versão final do museu 3D

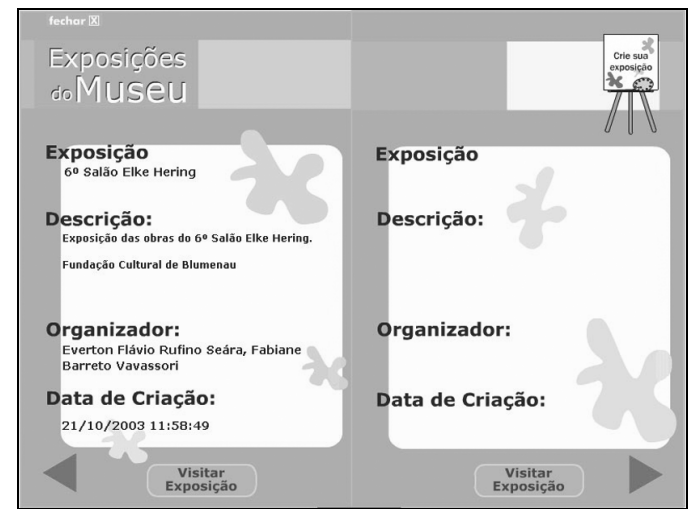

Figura 7(b) - Folder de apresentação

O foco deste artigo está no processo de desenvolvimento, mais detalhes sobre a escolha da tecnologia e funcionalidades implementadas no cenário do Museu podem ser encontrados em Seára et al. (2004).

\section{Conclusão}

Tendo em vista a complexidade envolvida no desenvolvimento de software educacional, principalmente no que tange aspectos de interdisciplinaridade presentes, considera-se que o processo proposto vem auxiliar a equipes envolvidas com construção de software educacional, visto que o mesmo define as etapas previstas no processo, identifica atividades e auxilia na composição da equipe, demarcando o papel de cada ator no processo de desenvolvimento.

O curto espaço de tempo para prover resultados e a dificuldade em visualizar um produto de software por grande parte dos profissionais de educação, faz com o que a utilização da prototipação evolucionária, internamente ao processo de elaboração, seja de grande importância uma vez que propicia o aprimoramento e debate de aspectos do software de forma incremental. Além disso, para os educadores ela permite melhor entendimento e visualização, uma vez que os mesmos mantêm constante contato com o produto, aumentado assim, a participação e as contribuições de fundo educacional. Desta forma, o processo de desenvolvimento é acelerado, pois ao fim de cada incremento é gerado um produto operacional, isto é, que pode ser utilizado de forma independente.

É de extrema importância observar na etapa de viabilização o feedback dos objetivos de aprendizagem, pois, mesmo que tenham sido traçados dentro da especificidade de V. $3 \mathrm{~N}^{\circ} 1$, Maio, 2005 
cada cenário, a formação e o acompanhamento, atividades desta etapa, têm demonstrado que objetivos inicialmente delineados podem ser alcançados, mas também podem ampliar seu escopo, ou seja, apresentar maior amplitude, caso ocorrido no projeto Softvali.

Espera-se que este processo de desenvolvimento contribua no que diz respeito à concepção de softwares educacionais, uma vez que sua aplicação tem demonstrado grande desempenho e facilidade de utilização em desenvolvimentos realizados pela equipe citada neste artigo.

\section{Agradecimentos}

Ao $\mathrm{CNPq}$ pelo financiamento do projeto de pesquisa. Ao Mestrado em Educação/UNIVALI e Secretaria Municipal de Blumenau pela parceria no projeto.

\section{Referências Bibliográficas}

Bertoletti, A.C.; Moraes, M.C.; Costa, A.C.R. Avaliação do módulo de aprendizagem do museu virtual SAGRES quanto a usabilidade de um software educacional. In: SIMPÓSIO BRASILEIRO DE INFORMÁTICA NA EDUCAÇÃO,12., 2001, Vitória. Anais. Disponível em: <http://www.inf.ufes.br/ sbie2001/>. Acesso em: 31 mar. 2005.

Blender3D. Página da Fundação Blender3D. Disponível em:<http://www.blender3d.org>. Acesso em: 8 jun. 2004

Hinostroza, J.E.; Mellar, H. Pedagogy embedded in educational software design: report of a case study. In: Computers \& Education, n.37, p.27-40, 2001.

IBM Software. Rational Unified Process: product overview. Disponível em: <http://www-306.ibm.com/software/awdtools/rup/>. Acesso em: 6 Jul. 2004

Ramos, E.M.F. (Org.). Informática na escola: um olhar multidisciplinar. Fortaleza: Editora UFC, 2003.

Seára, E.F.R; Benitti, F.B.V; Raabe, A.A.; Schlindwein, L.M. Da concepção à validação de um cenário virtual 3D para o Ensino Fundamental. In: WORKSHOP SOBRE INFORMÁTICA NA ESCOLA, 10., 2004, Salvador. Anais. Salvador: UFBA. 2004. (CD-ROM)

Simões, A. Folha do Alcino:guião para a produção de um hiperdocumento educativo. 2003. Disponível em: < http://www.prof2000.pt/users/folhalcino/tec_educ/site_do /guiao.htm>. Acesso em: 16 jun. 2004.

Sommerville, I. Engenharia de Software. 6. ed. São Paulo: Pearson Education do Brasil, 2003.

Trebien, E.S.E. Software educacional: modelo de desenvolvimento. União da Vitória: Face, 2003. 